Draft version of a Chapter for an edited text due for publication 2017

Bartley, A. and Beddoe, E. (eds) (2017)

Transnational Social Work: Opportunities and Challenges of a Global Profession

Chapter 2

\title{
Opportunities and challenges of a global profession: an international perspective
} Karen Lyons

This chapter presents material about the international context within which social work has developed. Social work is a global profession but one which shows considerable variation in its history, education and practices between countries, posing particular challenges for transnational social workers. The chapter questions the extent to which the global definition and international ethical code and education standards are widely understood or applied, weakening their possible utility for transnational social workers. The chapter goes on to acknowledge that many social problems are international in nature and that social workers would recognise the issues and client groups common across national borders. However, the way that services are organised and the expected responses of social workers show significant variations between countries, with implications for local practices. Finally, the chapter identifies some of the commonly reported strengths of transnational social workers but argues that these are often undervalued due to their positioning as incomers to a system and, therefore, as learners.

Keywords: Transnational social worker, international definitions and standards, contextual differences, social worker expectations and experiences

\section{Introduction}

Social work is generally understood to be an essentially 'local' activity, rooted in the socioeconomic conditions and political and legal systems of a particular country. Social workers generally intervene when problems occur at the interface between individuals, families and communities and their environments. Some aspects of human functioning (including relationships) might be regarded as universal, but behaviours are likely to be affected by the cultural traditions of a whole society or by the norms of sub-groups within it. Thus, there is an expectation that social workers 'understand' the local context and are 'able to communicate with' people in a particular locality. 
However, over the past century, social work has been increasingly accepted as also having an international dimension and is, on occasion, even transnational in some of its practices. This has become more pronounced with the recognition of globalisation as a process which pervades all aspects of life in all societies (to a greater or lesser extent) and with the inter-dependency which ensues. Many social problems can now be understood as being global in scope - and perhaps having international origins - as well as having distinctive impacts on local populations (Healy and Link, 2012; Lyons et al, 2012; Lyons, 2015).

Migration, while not a new phenomenon, is a particular feature of contemporary life in relation to the scale of population mobility and the number of countries between which people now move. Distinctions are sometimes made between 'asylum seekers' (who may in due course qualify under UN definitions as refugees) and 'economic migrants' with the assumption that this is an unwanted move for the first group but a personal choice for the second resulting in them being labelled as 'deserving' or 'undeserving' of official help. But these are simplistic and unhelpful dichotomies, when many people who leave their home countries can be regarded rather as being somewhere on a continuum of 'forced migration' from conflict, persecution, environmental causes through to crippling economic hardship. Migration, in turn, contributes to the interdependency of different countries, communities and families, while also persuading governments and international bodies to take steps to promote (or prevent) different forms of migration or the movement of particular groups or individuals (Fiddian-Qasmiyeh et al, 2014).

As mentioned, international labour mobility is one aspect of migration and is itself a diverse phenomenon, which has given rise to international conventions and policies and bilateral and multilateral agreements. Workers in professional fields may be seen as having a privileged status in relation to the wider body of those migrating for work reasons since they are presumed to have desirable skills which are transferable and there may be particular incentives for them to move to different countries. In the case of social work, the extent to which international labour mobility is a personal and/or professional choice, a response to a particular recruitment drive, or influenced by other 'push/pull' factors is variable and is not fully researched. However, like the social care workers included in a study by Christensen and Guldvik (2014), they are presumed to have agency, rather than being the victims of circumstance.

Over the last few decades there has been some research (reported in English language publications) into the motivations and experiences of internationally recruited doctors, teachers and nurses (and 
others in allied health and care professions), as well as social workers (Lyons and Littlechild, 2006; Walsh et al, 2010; Bartley et al, 2011). Indications from some of this literature are that transnational social workers may share similarities, in both motivation and experiences, with these other occupational groups (for example, Winkleman Gleed, 2006; Williams and Balaz, 2008; Guo and Singh, 2009). However, the particular nature of social work, with its emphasis on relationships and communication (whether with individuals, groups or communities), and the need for knowledge of the national policy, economic and legal contexts, may make social work harder to 'transplant' to different countries and present more challenges to transnational social workers.

This chapter presents the factors that contribute to the idea of social work as a global profession and suggests that international perspectives are relevant even in local practice; discusses the range of problems typically addressed by social workers and the extent to which these have international as well as local dimensions; and considers the strengths of, and challenges facing, transnational social workers, before a short concluding section about the particular contribution which this sector of the workforce makes to the internationalisation of social work.

\section{Social work as a global profession with international perspectives}

The beginnings of social work's recognition as an international profession occurred over a century ago, and were formally signified by a world conference in Paris in 1928 (Lyons and Lawrence, 2009). This, in turn, laid the basis for the three membership organisations which represent social work globally, today. The International Association of Schools of Social Work (IASSW, 2016) has a membership of over 400 schools worldwide (as well as individual and associate members) and a primary focus on professional education, while the International Council on Social Welfare (ICSW, 2016) has organisational members from the not-for-profit sector/non-governmental organisations (NGOs) from over 70 countries, primarily concerned with activities and advocacy in the social welfare, social policy and social development fields. The International Federation of Social Workers (IFSW, 2016) has members (national associations) from 116 countries representing over 500,000 social workers. Recently the three organisations, recognising their complementary strengths and the need to raise the international profile of social work and its role in contributing to social policy agendas, have produced a 'Global Agenda' and are in the process of establishing 'Regional Observatories' (Truell and Jones, 2014).

These three organisations are not the only international bodies in social work but they are perhaps the best known and longest established. In addition, less formal, more fluid and sometimes time- 
limited transnational academic, practice and research networks have periodically (and certainly over the last few decades) also been significant in raising the profile of social work at regional and international levels and contributing to the sharing and development of knowledge, including about comparative welfare and social work organisation and practice. However, for the purposes of this chapter, the focus here is upon the role of the three international bodies in contributing to our understanding of social work as a global profession and their efforts to establish international definitions, standards and guidelines that help us to identify common concerns and goals.

Since 2000, IASSW and IFSW have collaborated to produce three important international documents, the first of which was the 'International Definition of Social Work': the initial definition was agreed in 2000 and has recently been revised as the 'Global Definition of Social Work' (IFSW, 2014a). The 2000 definition became the basis for a 'Statement of Ethical Principles' and the 'Global Standards for the Education and Training of the Social Work Profession' (both were issued in 2004, see IFSW, 2016), both of which, together with the global definition, have continuing relevance, including in the context of international labour mobility in social work.

The first two sentences of the 'Global' definition state that 'social work is a practice-based profession and an academic discipline which promotes social change and development; social cohesion and the empowerment and liberation of people. Principles of social justice, human rights, collective responsibility and respect for diversities are central to social work' (IFSW, 2014a). Having this global definition of social work suggests that there is a shared, international understanding about the nature of social work - and thus the roles which social workers undertake in different national jurisdictions - facilitating international mobility and transnational social work. The definition itself is very broadly framed in order to take into account the wide diversity of national (and sometimes more local) understandings, mandates and practices of social workers and its authors suggest that the definition may be amplified at national and regional levels. However, the extent to which students at the qualifying stage are informed about this definition and have analysed its possible application in their own (national) situation - or considered its relevance to other jurisdictions - can be questioned, as can its inclusion in different forms of post-qualifying training. For example, the findings from a global survey of schools of social work carried out by IASSW suggest that 'international social work' does not feature significantly (if at all) in the curricula of most qualifying programmes (Baretta Herman et al, 2014).

Similar concerns can be expressed about the 'Statement of Ethical Principles' while the universality (or otherwise) of particular values in social work has been considered by various authors (for 
example, Healy, 2007; Hugman, 2013). As with the definition, the statement of ethical values is underpinned by a commitment to human rights and social justice and, while these may be uncritically accepted as common to social work internationally, the national conditions in which social workers operate may pose challenges in relation to respect for, and promotion of, both these values. At a general level, it has been suggested that the 'Ethical Statement' reflects a Western view which privileges the rights of individuals over the emphasis more often placed on family obligations and community interests reflected in the cultures of countries of the Global South. On another level, examples of value conflicts occur in relation to the treatment of some sub-groups in society. For instance, freedom of expression about sexuality is now widely accepted (relating to social attitudes and legal and policy terms) in most Western countries, although there may be some people within national populations (including some social workers) who, perhaps for religious reasons, would still deny this freedom. In other countries any deviation from heterosexuality is considered to be outside the accepted norms of human behaviour and might even be illegal, thus denying rights to people who would otherwise identify as part of the worldwide LGTB community. While persecution (actual or feared) on grounds of sexuality may be a motiving factor for some people to leave particular jurisdictions, it is far from universally accepted by the governments of receiving countries as a legitimate basis for granting asylum to some migrants. There is anecdotal evidence to suggest that some LGTB social workers themselves choose to seek work in countries which they perceive as having more tolerant social attitudes, particularly if this is backed by legislation against discrimination on grounds of sexuality, though it is not known whether this proposition has been formally researched. However, it is also possible that some transnational social workers bring with them prejudices about, for example, homosexuality which would not have been challenged in social work training in their countries of origin, notwithstanding a policy statement by IFSW (2014b) advocating for the inclusion of LGTB people and asserting the responsibility of social workers to protect and promote their rights and wellbeing.

Finally, regarding overarching statements framing social work at an international level, the document describing 'Global standards for social work education and training' sets out a range of standards in nine areas including those related to the core curriculum; expectations regarding fieldwork; and the qualifications of professional staff. The document is prefaced by a recognition of the 'context-specific realities' in which professional education for social work internationally takes place and an early commentary on the document described it as 'aspirational' rather than having a regulatory function (Sewpaul and Jones, 2004). Again, it is possible that having international standards might add weight to the efforts of professional educators to secure recognition and resources for social work programmes within their own higher education systems - but it cannot 
guarantee international conformity in the curricula and standards achieved by students on qualification. This can lead to a false sense of security about presumed similarities when considering how well equipped transnational social workers are to work in another jurisdiction and, in fact, most countries with well-established professional education programmes also have regulatory bodies with the competence to assess the comparability of 'overseas qualifications' presented by aspiring transnational social workers.

\section{Local and universal problems: different approaches and organisational issues}

Notwithstanding the limitations of international statements about and aspirations for social work in the face of the wide diversity in socio-economic, political-legal and cultural conditions in which social work is practised, it is possible to identify a range of social issues which social workers are commonly expected to address. Poverty was the basis for the origins of social work in the West and is currently a characteristic of many of the people with whom social workers interact worldwide (Cox and Pawar, 2006; Desai and Solas, 2012). Even in the Global North, relative poverty is still an issue although, for example, in the European Union, economic insecurity has more recently been labelled as part of a wider system of social exclusion and marginalisation of particular populations (Lyons and Huegler, 2013). People in such groups might be identified as members of a minority ethnic population or having a (particular kind of) disability and there are often related issues, such as poor living conditions, limited employment opportunities and health concerns. With regard to the last, Bywaters and Napier (2008) authored a paper which formed the basis for a policy statement by IFSW and an international network concerned with the significance of health issues and the role that social workers may play in contributing to policies and practices addressing the relevance of this issue for many aspects of social work practice, while Lyons et al (2006) had previously identified the international dimension of this issue.

In the West, social work strategies are frequently related to the assessed needs of individuals and families: workers have developed specialist skills (and sometimes have additional qualifications) and specialist agencies have often been established to address particular problems, such as child protection, elder abuse, substance misuse, homelessness or mental illness. In the Global South, policy concerns might focus on developing a social protection programme for a national population (Drolet, 2016) and a more community-orientated approach is represented in social development policies and projects. Social work 'specialisms' as individually tailored responses to the problems of particular population groups are generally less in evidence although they are sometimes 
addressed through the efforts of NGOs. The needs of vast populations in countries such as India or the Philippines have implications for the education and roles of social workers as well as their expectations about living standards and social work practices if they migrate to a Western country.

There are substantial differences between the structural and cultural determinants of the environments within which social work is practised even among 'developed' (as opposed to 'developing') countries (Nielson, 2011; Payne, 2012). For instance, major differences are evident between Europe and the US in the organisation and funding of various aspects of health and social care, affecting the role of social workers in these sectors (Hoffler and Clark, 2012; Zavirsek and Lawrence, 2012). The entrenchment of neo-liberal policies and the interests of capitalism have affected even the traditional 'welfare states' such as those long established in New Zealand, the Nordic countries and the UK, and the welfare systems of Canada and Australia have been similarly impacted (Teeple, 2000). The cultural aspect has been alluded to earlier and affects the extent to which societies expect family members or voluntary (including self-help and religious) organisations to address the needs of vulnerable people in the community. In addition, national populations often have minority groups, including Indigenous people, with different expectations and experiences of welfare systems (see Baines, this volume). These factors affect the roles of social workers and the resources and recognition available to them in particular countries in ways which are, perhaps, at variance with those of social workers who train in one country and work in another.

Over the last few decades, the IFSW, in particular, has produced a number of policy statements covering a wide variety of topics of importance to social work policies and practices. These result from particular motions put forward at general meetings, reflecting issues which have gained international, as well as, national importance. So, for instance, in 2014 a statement was issued on the protection of children from all forms of sexual abuse. This not only recognised the previously nationally identified concerns about incest and other forms of child sexual abuse, but also highlights the more recent concerns about (international) trafficking of children and young people for commercial sexual exploitation. Earlier policy statements have addressed a wide range of issues including 'Globalisation and the Environment'; 'Displaced people'; 'Poverty Eradication'; 'Indigenous People'; 'HIV/AIDS' and 'Cross-border Reproductive Services', indicating that these issues have international dimensions as well as local relevance. (These and other papers were all uploaded to a revamped website in 2012 and can be accessed through the current IFSW website, (IFSW, 2016).) 
One of these policy statements is perhaps of particular interest to transnational social workers since it concerns 'Effective and ethical working environments for social work: the responsibilities of employers of social workers' (IFSW, 2012). This document presents guidelines for provision of working environments which promote effective and ethical practice; protection of service user interests; and provision of (good) quality services, where the objectives of the organisation are aligned with those of the practitioners. It specifically suggests that the values and principles of the managers and social work practitioners should be consistent and mutually reinforcing. This suggests that the document is, in part, a response to the increased levels of managerialism experienced in what are often (in many Western countries) bureaucratic and/or budget-driven organisations.

The guidelines acknowledge that the context for social work practice varies according to local circumstances and recognises the variety of organisational contexts within which social workers are employed. These include secondary settings (such as schools and hospitals); local government; NGOs; for-profit companies; and user-led organisations, including co-operatives. The statement refers to the three core statements (see earlier) and describes the responsibilities of social workers as being to implement national policies; to safeguard human, social and economic rights; and to secure resources. Meanwhile, the document lists a number of agency responsibilities including to ensure the provision of effective induction, supervision, workload management and opportunities for continuing professional development (CPD). With the possible exception of the last, these are all factors mentioned in various studies as having a particular impact on the experiences (whether positive or negative) of transnational social workers (for example, Fouché et al, 2015; Hanna and Lyons, 2016; and chapters in this volume by Beddoe et al; Brown et al; and Walsh-Tapiata et al). The agency should also provide up-to-date written policies and guidelines and make appropriate use of research and regulatory frameworks.

While the agency needs to be 'consumer-facing' and have accessible procedures for complaints, it also has a 'duty of care' to its employees. As such, it should employ suitably qualified staff and have procedures in place to deal with dangerous, discriminatory or exploitative behaviour including minimising the risk of (and threats of) violence to social workers themselves. This suggests that the agencies in some countries - and certainly their staff - are operating in 'hostile' environments which can contribute to the professional culture shock sometimes experienced by transnational social workers. Some of them will be coming from countries where social workers have higher status or where the profession as a whole is subject to 'benign neglect', either condition seeming preferable to one where social workers feel, at best undervalued, and at worst, scapegoated, by the public and/or government for policy failings; and/or organisational or individual shortcomings 
(Hussein et al, 2011; Fouché et al, 2014).

\section{Transnational social workers: strengths and challenges}

Transnational social work practice is now a recognised aspect of social work internationally (Negi and Furman, 2010) and social workers who have their own experience of 'transnationalism' have much to contribute to national workforces. But being part of the transnational workforce is not without its challenges since, on one level, transnational social workers can simply be seen as part of a reserve army of labour, plugging the gaps in the labour force of particular countries. However, on more individual levels, transnational social workers bring with them a range of skills and expertise, although the extent to which social work agencies identify and build on these varies considerably. The lack of supportive environments and of policies for the induction, supervision and integration of transnational social workers have been commented on in several studies (as reported in this text) and undoubtedly contributes to the professional challenges facing transnational social workers.

As to their strengths, transnational social workers, by definition, bring with them important understandings of the processes of migration, resettlement and adaptation. It is assumed that only a relatively small proportion will have experienced the particular traumas of migration as asylum seekers but, nevertheless, they are likely to experience some of the feelings associated with loss, dislocation and culture shock (Casado et al, 2010). Their own experiences might contribute particularly to work with refugee or migrant populations but, having faced an unknown future, loss of familiar surroundings and support networks and the uncertainties and stresses surrounding adapting to new situations, they might also have an empathetic understanding of the needs of any service users facing life-changing situations.

In addition, the different contexts, cultures and professional backgrounds from which transnational social workers come can bring fresh perspectives to the work of colleagues, teams and agencies - if acknowledged. Similar to local social workers transferring from one agency or sector to another, transnational social workers often have quite specific knowledge about social work skills and methods which can be transferred and/or adapted for use in another context. However, this relies to some extent on the level of professional autonomy and openness to learning on the part of 'receiving organisations' and social workers in the host country. Like the doctors in the Williams and Balaz study (2008), even experienced workers might be identified as only 'learners' and, as Dominelli (2010) has stated, transfer of knowledge should not be assumed. This positioning of 
transnational social workers as 'incomers' and learners might prevent social work agencies from recognising and utilising new perspectives and alternative approaches to assessing problematic situations and ways of responding to them (see for example: Brown et al, 2014; Fouché et al, 2014). An example (from the UK) might be a reliance on individually based assessments and interventions at the expense of group- or community-based initiatives with which some transnational social workers would be very familiar.

The undervaluing of the possible contribution of transnational social workers is one of the particular challenges to this group of workers who can consequently feel quite 'deskilled' and unsure about their professional identity. These feelings are accentuated when faced with highly bureaucratised and/or legally based forms of social work where the 'new' social worker is on a steep learning curve regarding the policies, provisions and even rules of practice in particular agencies. While some aspects of human need and behaviour can be assumed to be universal - and international agencies might draw up conventions and guidelines relevant to social work values and practices the particular situations facing transnational social workers and the expectations of the agencies employing them can require high levels of adaptability and resilience or can even prove to be overwhelming for some transnational social workers.

One of the specific challenges facing transnational social workers relates to language. This operates on two levels. In the case of someone whose first language is not the same as the country to which they move, there is the specific challenge of learning the national language; this would not be 'from scratch' since people who have learned a new language to a standard acceptable for 'employment overseas' usually have skills in reading and writing. However, for a profession which is heavily dependent on verbal communication there are often challenges to transnational social workers in understanding (and becoming fluent in) local vocabulary usage, dialects and colloquialisms (Lyons and Littlechild, 2006; Harrison, 2013). On another level, even people who apparently speak the same language as the social workers in their new country, face a confusing barrage of new terms, acronyms and professional jargon, some of which would seem to belie the fact that social work is a global profession. This is apparent to anyone who has been involved in cross-national research projects where an international team usually has both the need and the opportunity to debate and 'translate' professional terms into words or even concepts which will be understood by social work respondents in different countries. In the case of transnational social workers, this 'translation work' is often a solitary pursuit but one which must be accomplished quickly in order to make sense of written directives, team discussions and so on. 
It is suggested that some of the challenges faced by transnational social workers arise from the assumptions which they and/or others make about the similarities between national education and training programmes and about the organisation of welfare and the role of social workers within the wider system. This applies particularly across English-speaking countries and when specific countries have a shared history. It is the case that, due to historical colonisation - and perhaps even the profession's more current international aspirations - particular approaches to the organisation of welfare and the training of social workers have been 'transplanted' from one jurisdiction to another. However, such homogenising influences often took place decades (even up to a century) ago and, despite the more recent spread of neo-liberal political ideas and economic austerity measures, individual countries have asserted their own paths to the development of welfare systems (including social services) and to the education and training of social workers. Thus, notwithstanding superficial similarities, some common policy trends, and the possible influence of international professional understandings, values and standards, individual countries have established different arrangements for delivering welfare and social services, and social work education itself is generally moulded to suit the particularities of a national context (for example, Pullen Sansfaçon et al, 2012; Noble et al, 2014), usually with scant regard for international perspectives (as mentioned earlier).

Much of the literature about the challenges facing transnational social workers - and indeed about the challenges to an international professional labour force more generally - concentrates on the stresses associated with adaptations and learning in the workplace. However, there are also personal and sometimes family-based pressures of adapting to life in a new society and a different culture, some of which have been identified in studies about expatriate workers in multinational companies (for example, EIU, 2010). It can be argued that in an occupation such as social work, where individual values and resources make an important contribution to professional performance, attention needs to be paid to the personal challenges being experienced in addition to those in the workplace and thought needs to be given to wider support possibilities.

\section{Concluding comments}

Notwithstanding the harsh climate prevailing at the time of writing with regard to immigration to many Western countries, it is likely that labour mobility will continue to be a feature of the global economy, including the transnational movement of qualified social workers. Such mobility raises important questions about the extent to which initial professional education and subsequent training include international perspectives and comparative dimensions as a way of orientating social 
workers to the varied forms which social work takes and the particular opportunities and challenges open to social workers in different national jurisdictions.

An important role of social workers in many countries and occupational positions is helping individuals and groups to obtain resources: transnational social workers may question what resources are needed and have different ideas about how best to access them. More importantly, transnational social workers are a resource in themselves, not just in the sense of 'plugging the gaps' in understaffed organisations but also regarding the particular attributes which they bring to this workforce.

Significant among these is their experience of the decisions and adaptations involved in migration itself. However, like other professional groups, there are usually major areas of difference regarding the cultures of various populations and organisations as well as professional 'ways of doing things'. Specific challenges highlighted by various national studies include attaining the right to work (including professional registration); securing a permanent post (with chances of advancement if their move is permanent); having their needs recognised as (usually) experienced workers who are also learners; and receiving appropriate support with regard to induction, supervision and ongoing professional development. These professional challenges are often experienced alongside the wider issues of adapting to the cultures and norms of a different country, sometimes with responsibility also for the local resettlement of other family members - or ongoing responsibilities to family members 'back home'.

But, as also recounted in some of the research studies, most transnational social workers demonstrate both adventurous and resourceful qualities and a strong desire to learn and succeed in their profession. Although there is now some literature in the migration field about 'circulatory migration' (for example, Flavell, 2008) there is, as yet, little research evidence, globally, to indicate what proportion of transnational social workers seek work in another country as a temporary opportunity, relative to those who see it as a more permanent life change for themselves (and sometimes also family members) - or those who relocate more than once and perhaps have work experience in more than two countries. In any case, transnational social workers are part of wider migration and settlement patterns which vary according to international and national events and policies, as well as individual circumstances. However, it is clear that some transnational social workers will sometimes settle long term, enriching the skills base and outlook of the profession in their 'new country', while others will return to their countries of origin - or move on elsewhere having questioned both old and new ways of working. All such social workers help us to develop a 
wider view of social work as a global profession.

\section{References}

Baretta Herman, A. Leung, P. and Littlechild, B. (2014) 'The changing status and growth of social work education worldwide: Process, findings and implications of the IASSW 2010 Census', International Social Work, doi:10.1177/0020872814547437.

Bartley, A., Beddoe, L., Duke, J., Fouché, C., Harington, P. R. J. and Shah, R. (2011) 'Crossing borders: Key features of migrant social workers in New Zealand', Aotearoa New Zealand Social Work, 23(3): 16-30.

Brown, M., Sansfaçon, A. P., Ethier, S. and Fulton, A. (2014) 'A complicated welcome: Social workers navigate policy, organizational contexts and socio-cultural dynamics following migration to Canada', International Journal of Social Science Studies, 3(1): 58-68.

Bywaters, P. and Napier, L. (2008) IFSW Policy Statement on Health, http://ifsw.org/policies/health/

Casado, B., Hong, M. and Harrington, D. (2010) 'Measuring migratory grief and loss associated with the experience of immigration', Research on Social Work Practice, doi:10.1177/1049731506360840.

Christensen, K. and Guldvik, I. (2014) Migrant care workers: Searching for new horizons, Farnham, UK: Ashgate.

Cox, D. and Pawar, M. (2006) International social work: Issues, strategies and programs, London: Sage. 
Desai, M. and Solas, J. (2012) 'Poverty, development and social justice', in K. Lyons, T. Hokenstad, M. Pawaret, and N. Huegler (eds) SAGE handbook of international social work, London: Sage, pp. 55-59.

Dominelli, L. (2010) Social work in a globalising world, Cambridge: Polity Press.

Drolet, J. L. (ed) (2016) Social development and social work perspectives on social protection, London: Routledge.

EIU (2010) Up or out: Next moves for the modern expatriate. A report from The Economist Intelligence Unit Ltd, http://graphics.eiu.com/upload/eb/lon_pl_regus_web2.pdf.

Fiddian-Qasmiyeh, E., Loescher, G., Long, K. and Sigona, N. (eds) (2014) The Oxford handbook of refugees and forced migration, Oxford: Oxford University Press.

Flavell, A. (2008) 'The new face of East-West migration', Journal of Ethnic and Migration Studies, 34(5): 701-16.

Fouché, C., Beddoe, L., Bartley, A. and de Haan, I. (2014) ‘Enduring professional dislocation: Migrant social workers' perceptions of their professional roles', British Journal of Social Work, 44(7): 2004-22, doi:10.1093/bjsw/bct054.

Fouché, C., Beddoe, L., Bartley, A. and Parkes, E. (2015) ‘Are we ready for them? Overseasqualified social workers' professional cultural transition', European Journal of Social Work, 19(1): 106-19, doi:10.1080/13691457.2015.1022858.

Guo, W. and Singh, M. (2009) 'Overseas trained teachers in Australia: A study of barriers, skills and qualifications', http://www.aare.edu.au/data/publications/2009/guo091408.

Hanna, S. and Lyons, K. (2016) “"London calling”: The experiences of international social work recruits working in London', British Journal of Social Work, doi.10.1093/bjsw/bcwo27. 
Harrison, G. (2013) ““Oh, you've got such a strong accent”: Language identity intersecting with professional identity in the human services in Australia', International Migration, 51(5): 192-204, doi:10.1111/imig.12005.

Healy, L. (2007) Universalism and cultural relativism in social work ethics, International Social Work, 50(1): 11-26.

Healy, L. and Link, R. (2012) Handbook of international social work: Human rights, development and the global profession, New York: Oxford University Press.

Hoffler, E. F. and Clark, E. J. (2012) Social work matters: The power of linking policy and practice, Washington, DC: NASW Press.

Hugman, R. (2013) Culture, values and ethics in social work: Embracing diversity, London: Routledge.

Hussein, S., Manthorpe, J. and Stevens, M. (2011) 'The experiences of migrant social work and social care practitioners in the UK: Findings from an online survey', European Journal of Social Work, 14(4): 479-96, doi:10.1080/13691457.2010.513962.

International Association of Schools of Social Workers. (2016) International Association of Schools of Social Workers website, www.iassw-aiets.org.

International Council on Social Welfare. (2016) International Council on Social Welfare website, http://icsw.org..

International Federation of Social Workers. (2012) Effective and ethical working environments for social work: the responsibilities of employers of social workers, http://ifsw.org/.

International Federation of Social Workers. (2014a) Global definition of social work, http://ifsw.org/policies/definition-of-social-work.

International Federation of Social Workers. (2014b) Sexual orientation and gender expression, http://cdn.ifsw.org/assets/ifsw_102638-5.pdf. 
International Federation of Social Workers. (2016) International Federation of Social Workers website, http://ifsw.org.

Lyons, K. (2015, online) 'Globalization, welfare and social work', in J. D. Wright (ed) International encyclopedia of social and behavioural sciences (2nd edn), Oxford: Elsevier, pp 262-67.

Lyons, K. Hokenstad, T. Pawar, M. Huegler, N. and Hall (eds) (2012) SAGE handbook of international social work, London: Sage.

Lyons, K. and Huegler, N. (2013, online) 'Social exclusion and inclusion' in Encyclopedia of social work, Oxford: Oxford University Press,

http://socialwork.oxfordre.cpm/view/10.1093/acrefore/9780199975839.001.0001/acre.

Lyons, K. and Lawrence, S. (2009) 'Social work as an international profession: Origins, organisations and networks', in S. Lawrence, K. Lyons, G. Simpson and N. Huegler (eds) Introducing International Social Work, London, Learning Matters/Sage, pp.108-121

Lyons, K. and Littlechild, B. (eds) (2006) International labour mobility in social work, Birmingham: BASW/Venture Press.

Lyons, K., Manion, K. and Carlsen, M. (2006) International perspectives on social work: Global conditions and local practice, Basingstoke, UK: Palgrave Macmillan.

Negi, N. J. and Furman, R. (eds) (2010) Transnational social work practice, New York: Columbia University Press.

Nielsen, L. (2011) 'Classifications of countries based on their levels of development: How it is done and how it could be done', IMF Working Paper (WP/11/31), http://www.imf.org./external/pubs/ft/wp1131.pdf.

Noble, C., Strauss, H. and Littlechild, B. (eds) (2014) Global social work education: Crossing borders and blurring boundaries, Sydney: University of Sydney/IASSW. 
Payne, M. (2012) 'Political and organisational contexts of social work internationally' in K. Lyons, T. Hokenstad, M. Pawar, N. Huegler and N. Hall (eds) SAGE handbook of international social work, London: Sage, pp 121-135.

Pullen-Sansfaçon, A. Spolander, G. and Engelbrecht, L. (2012) 'Migration of professional social workers: Reflections challenges and strategies for education', Social Work Education, 31(8): 1032-45.

Sewpaul, V. and Jones, D. (2004) 'Global standards for social work education and training', Social Work Education, 23(5): 493-513.

Teeple, G. (2000) Globalization and the decline of social reform: Into the $21^{\text {st }}$ century (2nd edn), Aurora, Ontario: Garamond Press.

Truell, R. and Jones, D. (2014) The Global Agenda for Social Work and Social Development: extending the influence of social work, http://edn.ifsw.org/assets/ifsw_24848-10.pdf accessed 24/04/16.

Walsh, T., Wilson, G. and O’Connor, E. (2010) 'Local, European and global: An exploration of migration patterns of social workers into Ireland', British Journal of Social Work, 40(6): 1978-95, doi:10.1093/bjsw/bcp141.

Williams, A. and Balaz, V. (2008) 'International return mobility, learning and knowledge transfer: A case study of Slovac doctors', Social Science \& Medicine, 67(19): 24-33.

Winkleman Gleed, A. (2006) Migrant nurses, motivation and contribution, Milton Keynes: Radcliffe Publishing.

Zavirsek, D. and Lawrence, S. (2012) 'Social work in Europe', in K. Lyons, T. Hokenstad, M. Pawar, N. Huegler and Hall (eds) SAGE handbook of international social work, London: Sage. 
